Web of Science Search

\section{Mechanical response of aluminum 7075 with heat treatment and exfoliation corrosion}

By: Kittur, MY (Kittur, Mohammad Yaseen) ${ }^{1}$; Kittur, MI (Kittur, M. I.) ${ }^{2}$, 3 ; Reddy, AR (Reddy, Avala Raji) ${ }^{4}$; Baig, MAA (Baig, Maughal Ahmed Ali) ${ }^{4}$; Ridwan (Ridwan) ${ }^{5}$; Khan, SA (Khan, Sher Afghan) ${ }^{5}$; Faheem, M (Faheem, Mohammed) 5, 6

View Web of Science ResearcherID and ORCID (provided by Clarivate)

MATERIALS TODAY-PROCEEDINGS

Volume: 47 Page: 6173-6179 Special Issue: SI Part: 17

DOI: $10.1016 /$ j.matpr.2021.05.081

Published: 2021

Document Type: Proceedings Paper

\section{Conference}

Meeting: International Conference on Technology Innovation in Mechanical Engineering (TIME)

Location: Bhopal, INDIA

Date: APR 22-23, 2021

Abstract

\section{Citation Network}

In Web of Science Core Collection

0

Citations

- Create citation alert

Cited References

\section{6}

View Related Records

Use in Web of Science

Web of Science Usage Count 
The present investigation was focussed to evaluate the mechanical properties of AA7075 subjected to corrosion and heat treatment. Exfoliation corrosion has been used to infuse rapid corrosion on the material coupled with high temperature and subsequent low-temperature aging (HLA). It has been found that the localized corrosion pit formation occurs with HLA and corrosion exposure durations with sı hstantial inter-granular chanoes and formation of cracks Significant reduction in

0

Last 180 Days

I nמrn marn

Add To Marked List

\section{0}

Since 2013

Full text at publisher

Export $\checkmark$

$<$ of $1>$

subjected to HLA and corrosion. (c) 2021 Elsevier Ltd. All rights reserved. Selection and peerreview under responsibility of the scientific committee of the Technology Innovation in Mechanical Engineering-2021.

\section{Keywords}

Author Keywords: AA7075; Exfoliation corrosion; HLA; Heat treatment; Mechanical properties; SEM

Keywords Plus: STRESS-CORROSION; LOCALIZED CORROSION; SCC-RESISTANCE; RETROGRESSION; STRENGTH; BEHAVIOR; ALLOY; MICROSTRUCTURE; FATIGUE; AA7050

\section{Author Information}

Corresponding Address: Faheem, Mohammed (corresponding author)

- VTU Belagavi, PA Coll Engn, Dept Mech Engn, Mangaluru, India

Addresses:

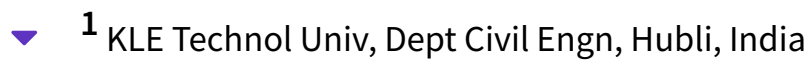

- 2 Univ Malaya, Fac Engn, Ctr Adv Mat, Kuala Lumpur, Malaysia

- 3 Univ Malaya, Fac Engn, Dept Mech Engn, Kuala Lumpur, Malaysia

${ }^{4}$ CMR Tech Campus, Dept Mech Engn, Hyderabad, Telangana, India

- ${ }^{5}$ Int Islamic Univ Malaysia, Fac Engn, Dept Mech Engn, Kuala Lumpur, Malaysia

...more addresses

E-mail Addresses: faheem.mech@pace.edu.in

\section{Categories/Classification}

Research Areas: Materials Science

\section{Document Information}

Language: English

\section{This record is from:} Web of Science Core Collection

- Conference Proceedings Citation Index Science (CPCI-S)

\section{Suggest a correction}

If you would like to improve the quality of the data in this record, please Suggest a correction 
Accession Number: WOS:000709741800005

ISSN: $2214-7853$

Other Information

IDS Number: WK5BW

- See fewer data fields

\section{Journal information}

MATERIALS TODAY-PROCEEDINGS

ISSN: $2214-7853$

Current Publisher: ELSEVIER, RADARWEG 29, 1043 NX AMSTERDAM, NETHERLANDS

Research Areas: Materials Science

Web of Science Categories: Materials Science, Multidisciplinary

26 Cited References

Showing 26 of 26

View as set of results

(from Web of Science Core Collection) 


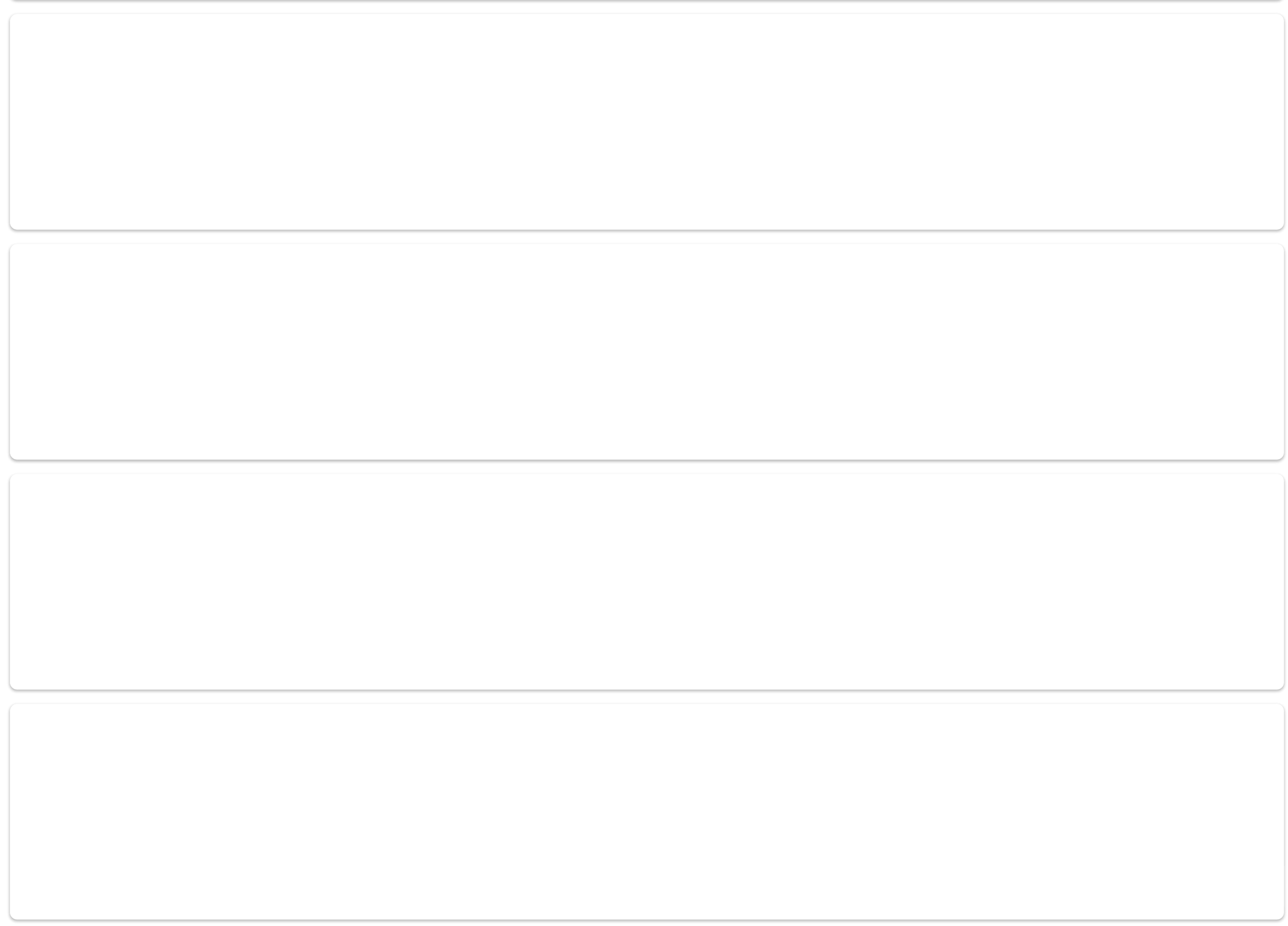




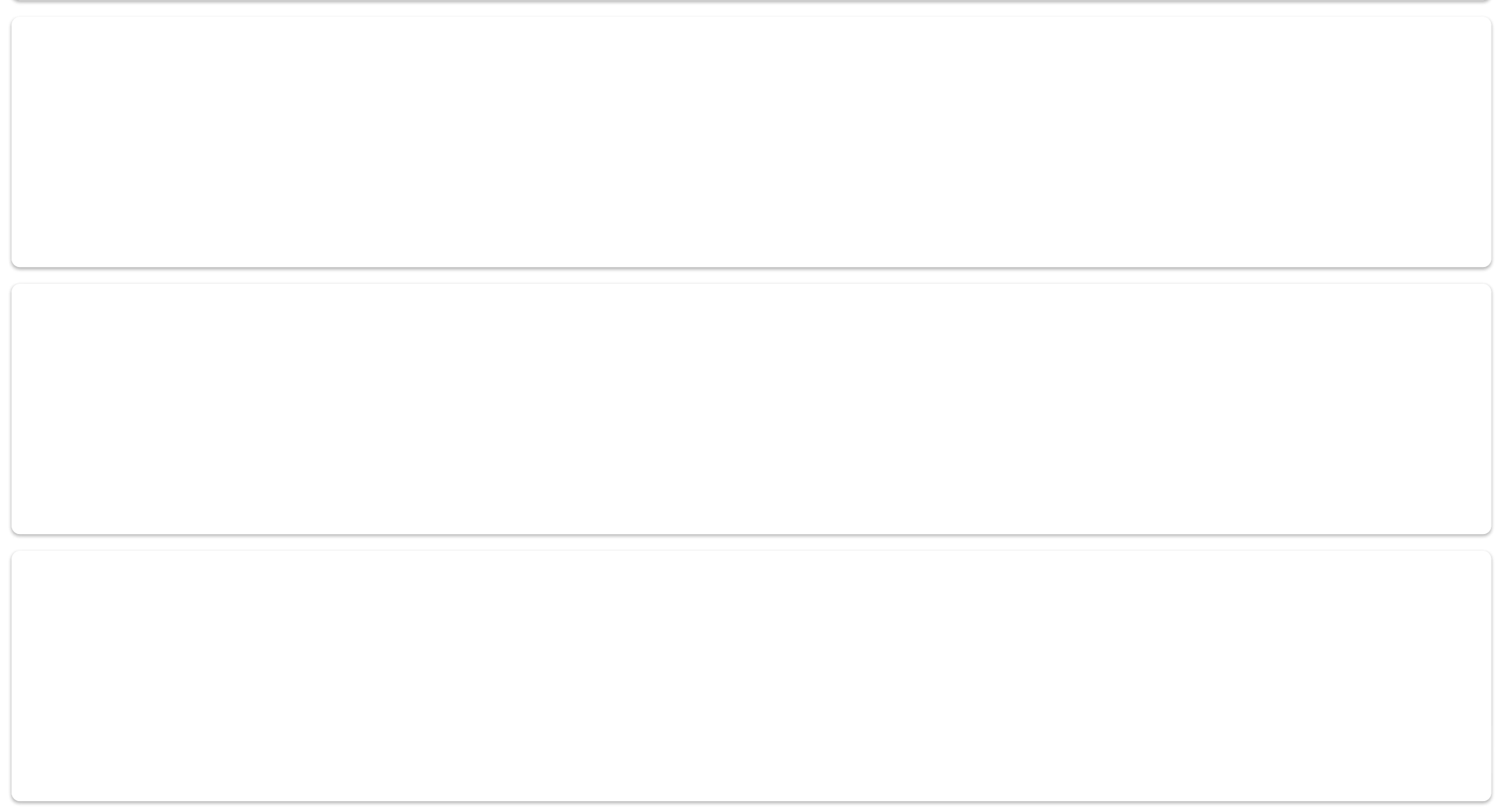



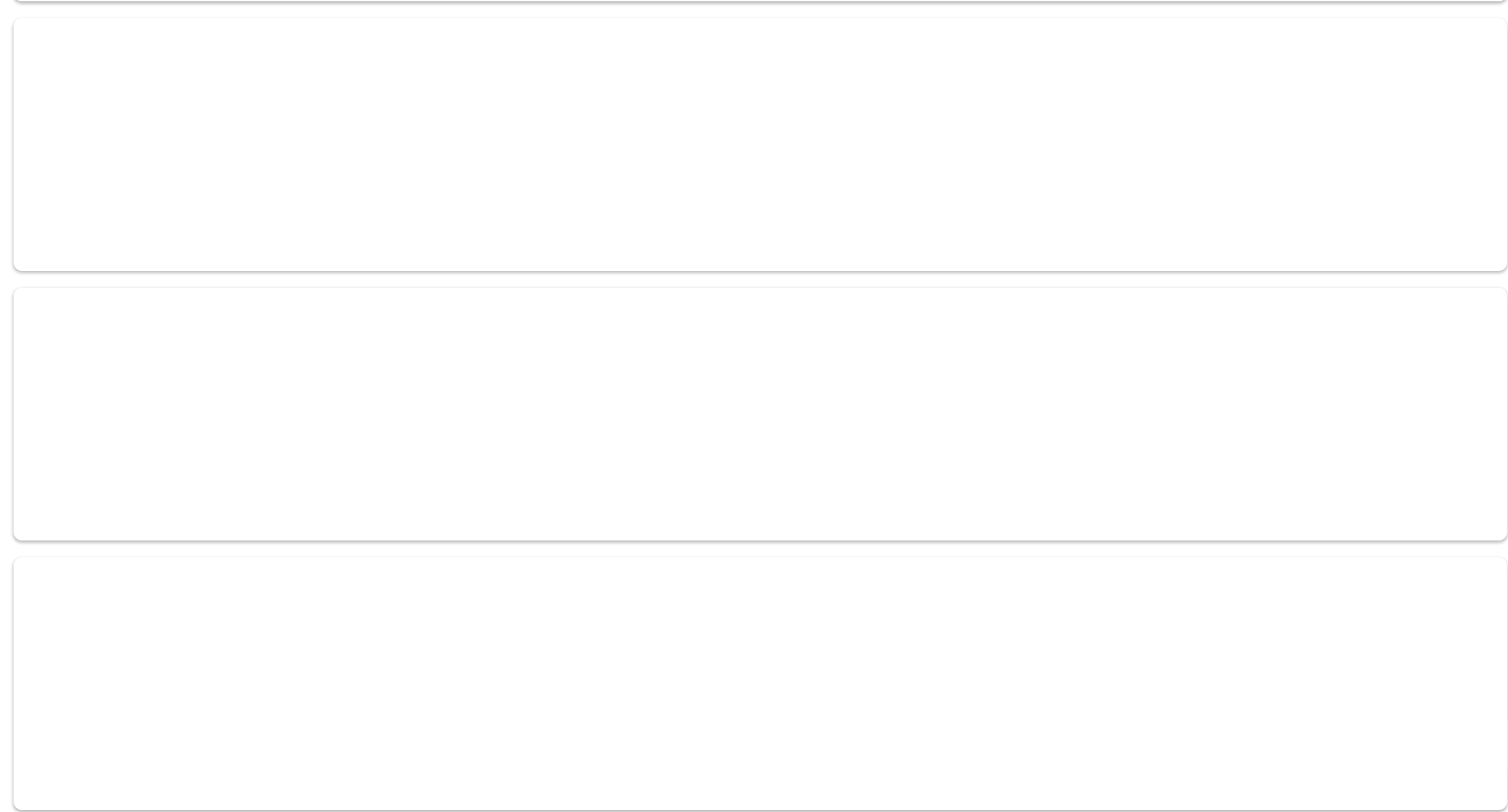


$\begin{array}{llll}\text { (c) 2021 Clarivate } & \text { Data Correction } & \text { Copyright Notice } & \text { Follow Us } \\ \text { Training Portal } & \text { Privacy Statement } & \text { Cookie Policy } & \text { Terms of Use } \\ \text { Product Support } & \text { Newsletter } & \text { T }\end{array}$

